\title{
An Empirical Study on Students' Perception and Satisfaction towards Online Assessment and Testing in Tertiary Education
}

\author{
${ }^{*}$ Truc T.T. Tran ${ }^{1}$, Phuong L.A. Nguyen ${ }^{2}$, Ngan H.T. Nguyen ${ }^{3}$, Du T. Tran ${ }^{4}$ \\ ${ }^{1}$ University of Social Sciences and Humanities - VNU-HCM. Email: thanhtructran@hcmussh.edu.vn \\ ${ }^{2}$ University of Social Sciences and Humanities - VNU-HCM. Email: phuongnguyennvn@hcmussh.edu.vn \\ ${ }^{3}$ University of Social Sciences and Humanities - VNU-HCM. Email: nht.ngan@hcmussh.edu.vn \\ ${ }^{4}$ Thu Dau Mot University.Email: dutt@tdmu.edu.vn \\ *Corresponding author.Email: thanhtructran@hcmussh.edu.vn
}

\begin{abstract}
The aim of this paper is to carry out an empirical study on students' satisfaction with online assessment and testing at some foreign language faculties at the University of Social Sciences and Humanities-Vietnam National University-HCM (USSH-VNU-HCM). Data were obtained by giving questionnaires to students at three faculties: Faculty of English Linguistics, Faculty of Russian Linguistics and Faculty of Chinese Linguistics. The questionnaire received 201 valid responses. Quantitative techniques were applied to find out some highlights from the results. (1) Students rated their perceived satisfaction from online testing as 4.08 on the 5-point Likert scale. (2) T-test showed that in comparison between faculties, students of the Faculty of English Linguistics and the Faculty of Russian Linguistics had similar views on the application of online assessment and testing. In contrast, the degree to which students of the Faculty of Chinese Linguistics supported online testing significantly differed from those of the other faculties. (3) Findings proved that most students in the experiment approved the continuation of the online assessment and testing after the pandemic, yet ANOVA results showed a considerable difference according to the faculty where students reside. (4) Correlation of contributing factors and students' willingness towards online testing continuation showed that there were strong associations between students' willingness and the three groups of factors: test organization factors, test content factors and grading factors. The study has obtained profound feedback from students, which helps to identify the challenges that online assessment and testing may encounter in the future.
\end{abstract}

Keywords: online assessment, testing, foreign language teaching, empirical study.

\section{INTRODUCTION}

In recent times, online teaching has become more and more widespread in the educational environment throughout the world. There have been numerous professional training programs, courses, or subjects at universities and research institutions worldwide that integrate teaching between traditional and online techniques (blended-learning). This trend is reinforced by the widespread implementation of the Learning Management System (LMS) in higher education (Stone 2014 \& Zheng) [9]. As a result, the use of online assessment and testing has rapidly grown, especially has been popular in online language teaching and learning.

The sudden expanding fourth wave of pandemic broke out in Vietnam in May 2021 forcing all educational activities to be immediately switched to online format. According to the official dispatch № 1415/UBND-VX, educational organizations are being obliged to work with students virtually in order to limit the dangers of coronavirus propagation [25]. USSHVNU-HCM then issued the notification № 250/TBXHNV-ĐT requiring the transfer of all face-to-face classes, including lectures, practical, and even laboratory sessions with virtual equivalents, to an 
online environment [33]. Instructors are compelled to structure the educational process using remote learning technologies based on various means of providing electronic material and available communication tools. However, due to the long-term social isolation, instructors ought to accordingly adjust to appropriate online evaluation formats, assuring students' learning progress. Assessment forms are selected and constructed in accordance with the legal basis and current regulations in decisions № 25/2006/QĐ-BGDĐT, № 43/2007/QĐ-BGDĐT, as well as the circular № 08/2021/TT-BGDĐT for undergraduate students enrolled prior to and after the $3^{\text {rd }}$ of May $2021[18,19,20]$.

Based on the legal basis guides of the Ministry of Education, USSH-VNU-HCM decided to apply LMS into online assessment and testing in July 2021. This was the first time USSH-VNU-HCM used this system to assist the teaching and assessment process. LMS technical support courses were provided for instructors to guide them on how to use LMS in testing. Instructors chose and built assessment forms in compliance with current regulations and technological infrastructure. In addition, USSH-VNUHCM students expressed certain concerns about eassessments. As reported by the studies of Boud and Olofsson et al., assessment is considered to be the biggest motivation for students, which drives their choices of when and how to study [8,3]. Since grading is being determined online, students want to ensure that their achievements will not be diminished by technical issues [28]. Fairness was proved to be students' main concern [14]. Being unable to observe other students during exams, they question if their classmates are cheating during exams. Being aware of these issues, test consultancy meetings at USSHVNU-HCM were set up online by instructors to give students the opportunity to raise their questions and concerns related to online assessment and testing.

Teaching and learning virtually require much consideration and preparedness before the educational programs take place. However, the sudden changes in assessment and testing approach (from face-to-face to online) in USSH-VNU-HCM would definitely have a certain impact on students' perception and performance. Therefore, it is a must to consider the students' views regarding online assessment and testing to ensure a smooth and effective application of online exam practice. Understanding students' perception and satisfaction towards online assessment and testing helps identify the main problems in implementing online assessments in higher education. Once students' viewpoints are identified, faculties and universities can accordingly boost the teaching methodology and online testing technology for the purpose of successful e-assessments.

Aiming to explore the viewpoint on online assessments and testing of students who are studying foreign languages in USSH-VNU-HCM, this study seeks the answers to these research questions:

a. What are the foreign language students' attitudes towards the online assessment organized by the university? Are there any differences between the faculties?

b. To what extent do the students satisfy with different components of the virtual assessment carried out during the pandemic?

c. Do participants' perceptions about the assessment practices differ according to the faculty's preparedness and implementation?

d. Will students decide to take online tests in the future? Which assessment factors affect the students' decisions?

\section{LITERATURE REVIEW}

According to R. Benson and C. Brack, "assessing" is related to all the activities and processes involved in evaluating the outcomes of academic activities. There are two types of assessment: formative and summative. Formative assessment plays a vital role in the improvement of performance. Summative assessment, on the other hand, is the final assessment of performance. This group of authors also outlines the various forms of online assessment in Table 1 below [26]:

Table 1. Forms of online assessment

\begin{tabular}{l|ll}
\multicolumn{1}{c|}{ Uses } & \multicolumn{2}{c}{ Examples } \\
\hline Online discussions & $\bullet$ & Roleplays \\
& $\bullet$ & Allocated roles \\
& $\bullet$ & Forums \\
& $\bullet$ & Debates \\
\hline Web publishing & $\bullet$ & E-portfolios \\
& $\bullet$ & Webpages \\
& $\bullet$ & Shared documents \\
\hline Submission of items & $\bullet$ & Media: image, audio, video, \\
for assessment & & presentation \\
& $\bullet$ & Essays \\
& $\bullet$ & Reviews \\
& $\bullet$ & Reports \\
\hline Automated & $\bullet$ & Drag and drop \\
assessment: & $\bullet$ & Matching \\
quizzes, multimedia & $\bullet$ & True/false \\
& $\bullet$ & Fill blanks \\
& $\bullet$ & Calculation \\
& $\bullet$ & Short answer \\
& $\bullet$ & Multiple choice \\
& $\bullet$ & Simulations \\
& &
\end{tabular}


A. Weleschuk et al. defined online assessments as "any way of assessing students' performance, offering feedback, or pushing students along in their learning process is completely online credit courses [2]." When assessing students, there are two types of assessments: summative, which is used to grade students against a set of standards or criteria and formative, which is used for monitoring students' development [1].

"Assessment" defined by S. Koç, X. Liu and P. Wachira refers to the systematic process of tracking learning through measurement, which is used to evaluate knowledge, skills, dispositions, or beliefs acquired throughout instructional sequences, intending to improve all aspects of student learning. This group of authors also divides assessment into two main types called "summative" and "formative". Summative assessment occurs in the final part of the learning process and consists mainly of concluding projects or standardized examinations, whereas formative assessment is considered a constant process throughout the learning sequence [31]. While choosing the type of assessments, some quality criteria should be reviewed to guarantee that the assessment objectives are satisfied, such as validity, reliability, clarity, and avoiding susceptibility for technical problems [12].

Assessment design and implementation have a significant influence on students' achievement than the mechanism of assessment delivery (online vs. offline). Countless studies have discovered no difference in students' performance and grades in online and offline course assessments [5, 15, 17, 24]. There is also no correlation between students' performance on online exams and his/her preferences or level of familiarity with technology [5].

Several recent studies addressed online assessment in the higher education sector. F.J. García-Peñalvo et al. presented a set of recommendations for eassessment in tertiary education [11]. Similarly, in response to emergency remote teaching due to the COVID-19 pandemic, A.F.A. Rahim developed nine guidelines for online assessment [4]. The study of R.X. Thambusamy and P. Singh measured the efficiency of online assessment in evaluating student learning in higher education [27].

In another research, S. Bhebhe and C. Maphosa discussed the significance of assessment in learning, conventional instructor-centered exams, online assessment approaches, cheating in online assessments and how to avoid it [29]. Also, I. Fitriyah and M. Jannah analyzed the positive and negative features of online assessment on students' learning behavior with the help of a small survey conducted at one of the Islamic universities in Kediri. The research by these authors revealed that students have a positive attitude toward the administration of the online assessment, and even both teachers and students are ready to face online assessment in the future [13]. For the formative assessment, the study of S.H.P.W. Gamage et al. focuses on the techniques used to create and review quizzes. After watching interactive videos from 2 to 6 times, $65 \%$ of students tried all formative questions, indicating that they were engaged and contented with the formative assessment [32].

In the current context of education, very few studies examined students' satisfaction of online assessment in Vietnam. On the contrary, several studies have been conducted overseas on this issue. However, most of these studies are limited in scope to either an overview of assessment methods and tools or a generalization of assessment methods and tools for a particular subject in online teaching. In addition, as online assessment was first implemented at USSH VNU-HCM, the university management, lecturers and students faced various challenges. Thus, our study concentrates on investigating the relationship between the implementation of online learning activities and students' perceived satisfaction, as well as the factors that affect the process of assessment and testing activities. With the help of data collected from students of three foreign language departments at USSH - VNU-HCM, the study aims to assist the university leaders and instructors improve and overcoming the shortcomings of the online teaching assessment and testing in the context of the COVID19 pandemic and in the coming time after the pandemic.

\section{METHODOLOGY}

\subsection{Participants}

In August 2021, an online questionnaire was sent through the Google survey platform to 344 Vietnamese students studying at USSH-VNU-HCM at three faculties: Faculty of English Linguistics (FEL), Faculty of Russian Linguistics (FRL) and Faculty of Chinese Linguistics (FCL). There were 201 participants completing the questionnaire resulting in a return rate of $58.4 \%$.

Among these participants, $28.9 \%$ of them $(n=58)$ were FEL students, $18.9 \%$ of the participants $(n=38)$ were FRL students, and 52,2\% of the participants $(\mathrm{n}=$ 105) were FCL students. We aimed to obtain the number of each faculty's participants higher than $50 \%$ of the total sample of each faculty. For FEL, the questionnaire received $56.9 \%$ responses from the total 
sample. For FRL, there were $71.5 \%$ responses from the total sample. And for FCL, the percentage was $55.5 \%$ as similar to FEL. Participants were informed of the academic purposes of this study without addressing their identity or faculty name.

\subsection{Measurement and instruments}

In the questionnaire, a brief explanation of the research objective was mentioned in the first part of the survey, together with a definition of online assessment tools/ methods and the anonymity of the study. To differentiate faculties which the participants belonged to, a filter question was asked to classify them. The participants were explained to use a 5-point Likert scale ranging from "strongly agree" to "strongly disagree" to show their perception and satisfaction with online assessment and testing. In the second part of the questionnaire, students' satisfaction was assessed by 5 groups of factors: test organization, test consultancy, test content, technical infrastructure and grading factors. Each of these factors contained 4 questionnaire items.

Content validity was ensured by a two-step process. First, the questionnaire was sent to two professors from two different faculties for being reviewed and revised from their feedback. Second, two psychology professors reviewed the questionnaire to ensure that there were no common errors such as confusing questions or ambiguous sentences.

Descriptive statistics, independent t-test and ANOVA test were applied for data analysis of this study. The descriptive statistics of mean (M) and standard deviation (SD) showed the students' perceived satisfaction with online assessment and testing. Since there were three groups of students who were from three independent faculties, ANOVA and ttest were employed to examine if there were significant differences.

Apart from 20 questions defining students' perception and satisfaction, a concluding question was asked to measure students' attitudes towards future online assessment and testing after the pandemic. Similar to the above analysis, ANOVA was performed to examine differences between three groups of students. Then, the independent t-tests were conducted for three faculty pairs to determine whether those differences were significant.

\subsection{Data collection}

In this study, the target population was Vietnamese students who study foreign languages at USSH-VNU-
HCM. The questionnaire was sent via email to 12 professors from three different faculties - FEL, FRL and FCL. They were asked to send the questionnaire to their students. Therefore, the type of sampling is purposive sampling.

The research objective was to find out if participants' perceptions and satisfaction about the online assessment practices differ according to the faculty's preparedness and implementation. Therefore, purposive sampling was employed for this study.

Though belonging to different faculties, all participants had a comparable level of language competency (B1-B2 level). They had studied reading, listening, writing and speaking skills during the semester before the empirical study took place. They all took online tests for those language skills.

\subsection{Validity and reliability}

The normality of data collected in this study was identified by skewness and kurtosis indexes. These figures show a normal distribution of the obtained data, which is appropriate for parametric analysis. Cronbach tests in the study suggest that the reliability should be high and internally consistent. Skewness and kurtosis indexes were shown in Table 2, in which their absolute values are below three and ten, respectively, resulting in evidence that the deviation of data from normality was not severe.

Table 2. Validity and reliability indexes with Cronbach's alpha coefficient $(n=201)$

\begin{tabular}{clcccc}
\hline \multirow{2}{*}{ Faculty } & Factors & $\begin{array}{c}\text { \# of } \\
\text { items }\end{array}$ & Skewness & Kurtosis & $\begin{array}{c}\text { Cronbach's } \\
\alpha\end{array}$ \\
\hline \multirow{3}{*}{$\begin{array}{c}\text { FEL } \\
(\mathbf{n = 5 8})\end{array}$} & Test organization & 4 & -2.66 & 9.09 & 0.74 \\
\cline { 2 - 6 } & Test consultancy & 4 & -1.46 & 2.23 & 0.80 \\
\cline { 2 - 6 } & Test content & 4 & -1.11 & 0.42 & 0.79 \\
\cline { 2 - 6 } & Technical infrastructure & 4 & -1.61 & 3.18 & 0.83 \\
\cline { 2 - 6 } & Grading & 4 & -0.60 & -0.77 & 0.83 \\
\hline \multirow{3}{*}{$\mathbf{F R L}$} & Test organization & 4 & -1.02 & 0.67 & 0.59 \\
\cline { 2 - 6 }$(\mathbf{n = 3 8})$ & Test consultancy & 4 & -1.96 & 3.66 & 0.73 \\
\cline { 2 - 6 } & Test content & 4 & -0.84 & 0.32 & 0.83 \\
\cline { 2 - 6 } & Technical infrastructure & 4 & -0.77 & 0.08 & 0.75 \\
\cline { 2 - 6 } & Grading & 4 & -0.97 & 1.28 & 0.83 \\
\hline \multirow{2}{*}{$\begin{array}{c}\text { FCL } \\
(\mathbf{n = 1 0 5 )}\end{array}$} & Test organization & 4 & -0.36 & -0.61 & 0.74 \\
\cline { 2 - 6 } & Test consultancy & 4 & -0.84 & 0.22 & 0.82 \\
\cline { 2 - 6 } & Test content & 4 & -0.53 & 0.21 & 0.83 \\
\cline { 2 - 6 } & Technical infrastructure & 4 & -0.29 & -0.53 & 0.79 \\
\hline & Grading & 4 & -0.29 & -0.54 & 0.78 \\
\hline
\end{tabular}

Table 2 shows Cronbach's alpha coefficients. According to Carmines and Zeller, Cronbach's alpha should not be lower than 0.70 to ensure validity and reliability of the research [10]. In this empirical study, except for one questionable item (0.59), the Cronbach's alpha coefficients of the scales range from 
0.73 and 0.83 . This range is considerably significant and internally consistent.

\section{RESULTS}

\subsection{Attitudes towards the online assessment}

The descriptive statistics regarding students' perceptions about the assessment practices carried out online during the pandemic are presented in Table 2. The results show that students from the three faculties positively supported the online assessment and testing $(\mathrm{M}>3.80)$. Among the faculties, FEL students had the highest level of satisfaction ( $\mathrm{M}=4.55)$, while the FCL students' level was the lowest $(\mathrm{M}=3.80)$. FRL students' satisfaction was quite high $(\mathrm{M}=4.28)$ and similar to the level of FEL students $(\mathrm{M}=4.55)$.

Table 3. Descriptive of participants' perception about the online assessment

\begin{tabular}{cccccc} 
& Mean & SD & Variance & Skewness & Kurtosis \\
\hline FEL & 4.55 & 0.52 & 0.27 & -1.13 & 1.00 \\
\hline FRL & 4.28 & 0.49 & 0.24 & -0.81 & 0.14 \\
\hline FCL & 3.80 & 0.65 & 0.42 & -0.42 & -0.10 \\
\hline
\end{tabular}

According to Table 3 , there are differences in students' perceptions between the three faculties. However, Table 4 shows that the difference between the FEL and the FRL (0.27) was not significant, $t$ (83) $=1.62$. In contrast, the difference between the FEL and FCL (0.75) was statistically meaningful, $\mathrm{t}(141)=$ $6.98, \mathrm{p}<0.001$. Correspondingly, compared the perceptions of FRL and FCL students, the difference (0.48) was statistically valid, $\mathrm{t}(87)=4.73, \mathrm{p}<0.001$.

Table 4. Paired samples t-test

\begin{tabular}{lccccc}
\hline Pairs & $\begin{array}{c}\text { Mean } \\
\text { difference }\end{array}$ & $\mathbf{t}$ & df & Sig. (2-tails) \\
\hline FEL - FRL & 0.27 & 1.62 & 83 & 0.10 \\
\hline FEL - FCL & 0.75 & 6.98 & 141 & 0.000 \\
\hline FRL - FCL & 0.48 & 4.73 & 87 & 0.000 \\
\hline
\end{tabular}

\subsection{Different components of the virtual assessment affect students' satisfaction}

The data in Table 5 shows that students' satisfactions vary remarkably according to the assessment factors and the faculties to which students belong.

FEL students were highly satisfied with test organization and test content $(M=4.68$ and $M=4.58$ respectively). Grading factors were at the lowest level but still high compared to those of other faculties $(\mathrm{M}=4.31)$.
FRL students were highly content with test consultancy $(\mathrm{M}=4.73)$ and test organization factors $(\mathrm{M}=4.53)$, while technical infrastructure factors had the lowest level of satisfaction $(\mathrm{M}=3.55)$.

Regarding FCL, only test consultancy factors received students' high satisfaction $(\mathrm{M}=4.22)$. Technical infrastructure factors had the lowest level of satisfaction $(\mathrm{M}=3.44)$, whilst the three remaining factors had a relatively good response $(\mathrm{M}>3.56)$.

Table 5. Descriptive of participants' perceptions about various components of the online assessment

\begin{tabular}{llccc}
\hline \multirow{2}{*}{ Faculty } & Factors & $\begin{array}{c}\text { \# of } \\
\text { items }\end{array}$ & M & SD \\
\hline \multirow{3}{*}{$\begin{array}{l}\text { FEL } \\
(n=58)\end{array}$} & Test organization & 4 & 4.68 & 0.51 \\
\cline { 2 - 5 } & Test consultancy & 4 & 4.34 & 0.77 \\
\cline { 2 - 5 } & Test content & 4 & 4.58 & 0.52 \\
\cline { 2 - 5 } & Technical infrastructure & 4 & 4.34 & 0.76 \\
\cline { 2 - 5 }$(n=38)$ & Grading & 4 & 4.31 & 0.68 \\
\cline { 2 - 5 } & Test organization & 4 & 4.53 & 0.45 \\
\cline { 2 - 5 } & Test consultancy & 4 & 4.73 & 0.44 \\
\cline { 2 - 5 } & Test content & 4 & 4.34 & 0.63 \\
\cline { 2 - 5 } & Technical infrastructure & 4 & 3.55 & 0.82 \\
\hline \multirow{3}{*}{$\begin{array}{l}\text { FCL } \\
(n=105)\end{array}$} & Grading & 4 & 4.26 & 0.70 \\
\cline { 2 - 5 } & Test organization & 4 & 3.90 & 0.72 \\
\cline { 2 - 5 } & Test consultancy & 4 & 4.22 & 0.69 \\
\cline { 2 - 5 } & Test content & 4.88 & 0.77 \\
\cline { 2 - 5 } & Technical infrastructure & 4 & 3.44 & 0.90 \\
\cline { 2 - 5 } & Grading & 4.56 & 0.80 \\
\hline
\end{tabular}

\subsection{Faculty's preparedness and implementation affect students' satisfactions}

In terms of testing organization, the three faculties belong to the same university and receive the same online assessment regulations as well as technical infrastructure. In theory, students' satisfaction should be the same regardless of the faculties where they study. However, data in Table 6 show that there are differences in students' perceptions between the faculties. ANOVA results confirmed that students' perceptions differed significantly according to the faculty's preparedness, $\mathrm{F}>8.0, \mathrm{p}<0.001$.

Table 6. Participants' perceptions about various assessment components according to faculties

\begin{tabular}{lcccc}
\hline Factors & $\begin{array}{c}\text { Mean } \\
(\mathrm{FEL})\end{array}$ & $\begin{array}{c}\text { Mean } \\
(\mathrm{FRL})\end{array}$ & $\begin{array}{c}\text { Mean } \\
(\mathrm{FCL})\end{array}$ & $\begin{array}{c}\mathrm{F} \\
\text { ANOVA test }\end{array}$ \\
\hline Test organization & 4.68 & 4.53 & 3.90 & 34.15 \\
\hline Test consultancy & 4.34 & 4.73 & 4.22 & 8.03 \\
\hline Test content & 4.58 & 4.34 & 3.88 & 21.03 \\
\hline $\begin{array}{l}\text { Technical } \\
\text { infrastructure }\end{array}$ & 4.34 & 3.55 & 3.44 & 22.29 \\
\hline Grading & 4.31 & 4.26 & 3.56 & 23.59 \\
\hline
\end{tabular}


Test organization factors were highly satisfied both in FEL and FRL, whilst for FCL students, the factors received relatively weak responses $(M=3.90)$. Similarly, test content and grading factors had a high approval from FEL and FRL students, but the levels of satisfaction were lower in FCL $(\mathrm{M}=3.88$ and $\mathrm{M}=3.56)$.

\subsection{Students' viewpoints on the continuity of online assessment and testing in the aftermath of the pandemic}

Besides 20 questions related to the organization and implementation of the online assessment and testing, participants were asked if they agreed with the continuation of the online assessment and testing in the future (question 21). Table 7 presents the students' viewpoint in three faculties.

Table 7. Descriptive of participants' viewpoint on the future of online assessment and testing

\begin{tabular}{cccccc} 
& Mean & SD & Variance & Skewness & Kurtosis \\
\hline FEL & 3.77 & 1.34 & 1.79 & -0.84 & -0.40 \\
\hline FRL & 3.63 & 1.26 & 1.59 & -0.52 & -0.58 \\
\hline FCL & 2.82 & 1.44 & 2.08 & 0.18 & -1.27 \\
\hline
\end{tabular}

The results in Table 7 show that FEL and FRL students strongly supported the continuity of online assessment ( $M=3.77$ and $\mathrm{M}=3.63$ respectively) whilst FCL students expressed a weaker approval $(\mathrm{M}=2.82)$.

The One-way ANOVA test in Table 8 proves that there are significant differences in students' agreement on the form of future assessment and testing.

The t-test results show that in comparison between faculties, the difference between FEL and FRL (0.14) was not significant, $t=0.53$. In other words, FEL and FRL students had similar viewpoints on the future of online assessment and testing.

Compared with the other two faculties, FCL students had different viewpoints which were against virtual assessments in the future. These differences were statistically significant, $\mathrm{t}=3.23$ and $\mathrm{t}=4.20$ $(\mathrm{p}<0.001)$.

Table 8. ANOVA results on students' approval of the continuation of the online assessment

\begin{tabular}{lccccc} 
& SS & df & $\begin{array}{c}\text { Mean } \\
\text { Square }\end{array}$ & F & Sig. \\
\hline $\begin{array}{l}\text { Between } \\
\text { Groups }\end{array}$ & 40.22 & 2 & 20.11 & 10.54 & 0.000 \\
\hline $\begin{array}{l}\text { Within } \\
\text { Groups }\end{array}$ & 377.84 & 198 & 1.91 & & \\
\hline Total & 418.06 & 200 & & & \\
\hline
\end{tabular}

To further analyze these differences, an independent t-test between three pairs of faculties was employed. Results of the t-test are presented in Table 9.

Table 9: Paired sample t-test shows students' viewpoint on the continuation of the online assessment

\begin{tabular}{|c|c|c|c|c|}
\hline Pairs of faculties & $\mathbf{t}$ & $\begin{array}{c}\text { Mean } \\
\text { difference }\end{array}$ & Mean & SD \\
\hline FEL & \multirow{2}{*}{0.53} & \multirow{2}{*}{0.14} & 3.77 & 1.34 \\
\hline $\mathrm{FRL}$ & & & 3.63 & 1.26 \\
\hline $\mathrm{FCL}$ & \multirow{2}{*}{$3.23 * * *$} & \multirow{2}{*}{0.81} & 2.82 & 1.44 \\
\hline FRL & & & 3.63 & 1.26 \\
\hline FEL & \multirow{2}{*}{$4.20 * * *$} & \multirow{2}{*}{0.95} & 3.77 & 1.34 \\
\hline $\mathrm{FCL}$ & & & 2.82 & 1.44 \\
\hline
\end{tabular}

On investigating factors that influence students' viewpoints of continuing online assessment and testing, Pearson correlation analysis and significant test were employed to examine the associations between five components of assessment and student decisions on continuing online assessment. Table 10 presents the results of the analysis. The results show that the correlation varies considerably according to the faculty.

Table 10: Correlation analysis for various students' satisfaction factors on the continuation decision

\begin{tabular}{cccccc} 
Faculty & $\begin{array}{c}\text { Test } \\
\text { organization }\end{array}$ & $\begin{array}{c}\text { Test } \\
\text { consultancy }\end{array}$ & $\begin{array}{c}\text { Test } \\
\text { content }\end{array}$ & $\begin{array}{c}\text { Technical } \\
\text { infrastructure }\end{array}$ & Grading \\
\hline \multicolumn{2}{l}{ Pearson's correlation coefficient $(r)$} & & & & \\
\hline FEL & 0.23 & $0.33^{*}$ & 0.04 & 0.27 & 0.28 \\
\hline FRL & $0.40^{* *}$ & 0.32 & $0.42^{* *}$ & $0.49^{* *}$ & $0.44^{* *}$ \\
\hline FCL & $0.30^{* *}$ & 0.24 & $0.30^{* *}$ & 0.24 & $0.31^{* *}$ \\
\hline
\end{tabular}

* Correlation is significant at the 0.05 level (2-tailed)

** Correlation is significant at the 0.01 level (2tailed).

Pearson correlation analysis shows that in FEL, test consultancy factors $(r=0.33, p<0.05)$ are relatively related to students' approval of the continuation of online assessment and testing. In FRL, test organization factors $(\mathrm{r}=0.40, \mathrm{p}<0.01)$, test content factors $(\mathrm{r}=0.42, \mathrm{p}<0.01)$, technical infrastructure factors $(\mathrm{r}=0.49, \mathrm{p}<0.01)$, and grading factors $(\mathrm{r}=0.44$, $\mathrm{p}<0.01)$ are intensely connected with students' viewpoints of continuing online assessment in the future. Similarly, for FCL, test organization factors $(\mathrm{r}=0.30, \mathrm{p}<0.01)$, test content factors $(\mathrm{r}=0.30$, $\mathrm{p}<0.01)$, and grading factors $(\mathrm{r}=0.31, \mathrm{p}<0.01)$ are 
strongly associated with students' decision of supporting online assessment in the aftermath of the pandemic.

\section{DISCUSSION}

As the fourth wave of pandemics hit Vietnam in May 2021, resulting in lockdowns, all educational activities have been switched to the e-learning format, including online assessment and testing. Based on the legal basis guides of the Ministry of Education, USSHVNU-HCM issued new instructions and notifications for faculty leaders, instructors and students, which guided them on how to apply LMS into online assessment and testing. The fact that it was the first time LMS was applied to assessment and the preparedness for this application was made in a short time. It is vital to examine the perspectives of university students on e-assessment.

From the results of the study, this paper described the perception of online assessment and testing from students in a higher education institution - USSHVNU-HCM. The future of e-assessment is very promising based on the obtained results. The majority of students were in favour of online assessment adaptation in the pandemic context. Findings showed that overall, students positively supported the continuation of online assessment and testing after the pandemic. Students were convinced of the implementation of online assessment before they embraced it willingly. Correlation of contributing factors and students' willingness showed that the three groups of factors, test organization factors, test content factors, and grading, were strongly associated with students' willingness. Participants in other studies showed a similar preferable adaptation of online assessments and testing as observed by Lei et al. and Rolim \& Isaias, who confirmed that students and instructors also highly evaluate the accessibility of eassessments [16, 6]. In addition, our findings align very closely with the conclusion that students are flexible in approaching their testing in a distance education course as they are well instructed about eassessment by the faculty and institution [16].

This study shows evidence that how the transition from traditional face-to-face to online assessment is made plays a vital role in the acceptance of online assessments and testing. This finding seems to be consistent with the suggestion that changes should firstly be started from training students on technology usage [7]. The interaction between students and instructors related to online testing consultancy would make online assessment easier for students to accept and adapt, as was concluded in the findings of this study. Similarly, in other studies, additional support to familiarize students with online communication would guarantee students' awareness of their self-regulation and in-time assessment completion, as was concluded in the studies by Hung et al. and Kebritchi et al. [22, 21]

Furthermore, in terms of testing organization, the three faculties in the experiment belong to the same university and receive the same online assessment regulations as well as technical infrastructure. In theory, students' satisfaction should not considerably vary regardless of the faculties where they study. However, findings showed that there were noticeable differences in students' perceptions between the faculties. Thus, it is important that faculty's preparedness and implementation of institutional instructions should be considered. How instructors are trained and guided with technology in online testing would play a vital role in its successful application. As suggested by another researcher, perceived faculty needs and priorities should be considered before launching faculty development plans [23]. An application of using technology within low stake assessments at the early stage would make students feel at ease with the change before the transition to more crucial assessments in online format once could be adapted [30]. The conclusions of these researches have supportively corroborated our findings.

In this empirical study, technical infrastructure was observed to receive the lowest level of satisfaction from students of two faculties FRL and FCL. In the online learning environment, some students who are not familiar with technology have encountered certain difficulties. Some of them lack online learning aids such as laptops, smartphones or the Internet. Supportive alternative solutions provided by instructors, faculty leaders and IT department of USSH-VNU-HCM should definitely assist students overcome this issue in the future. Our findings are supported by another empirical study by Alenezi A. which revealed that the main obstacles of students' LMS participation were inadequate technical support by the universities, poor Internet access and networking, lack of hardware and software to run the LMS [1]. This poses some challenges for higher education institutions to make a greater effort to enhance LMS application in the virtual learning environment in the future.

This study focuses on examining the foreign language students' perspectives of online assessments and testing. Therefore, purposive convenience sampling was employed. The main drawback of purposive sampling is that it is prone to researchers' 
bias. However, the study focuses on students who belong to different foreign language faculties yet shared the same experience of testing methods and tools for the same certain subjects they had during the semester. The aim is to shed light on the common experience of e-assessment shared by the participants in the study. As a result, the findings are not generalizable and cannot represent the whole university students' population. To add greater value to the study, further researches could be conducted by making comparisons of perspectives from students in different majors and disciplines.

\section{CONCLUSION}

Findings of this study suggest that students' perception of online assessment and testing should be thoroughly considered. Although the results showed that the majority of students supported online assessment adaptation, students' satisfaction differed significantly according to the faculty's preparedness. Contributing factors towards students' approval of eassessment were: test organization factors, test content factors and grading factors. Gaining lower acceptance from students, technical infrastructure factors, and test consultancy factors pose a challenge for instructors, faculty and university leaders in providing extra support for students who have difficulties accessing the system to ensure students' interests and benefits.

In conclusion, the design and implementation of good e-assessments require careful preparedness and thoughtful consideration of the following factors: the students' objectives and background, the course content, the academic outcomes and technical infrastructure. To ensure the practicality of the transition to online assessment, instructors, faculty and university leaders must also consider how technology will interact with each of these factors to identify what challenges online assessment and testing have faced in the learning process. Further studies on instructors' practice of e-assessment and institutional implementation of online testing could be carried out to provide a deep understanding of the current issue of e-assessment transition in foreign language teaching and learning.

\section{AUTHORS' CONTRIBUTIONS}

All authors helped design and carry out the research. Truc T.T. Tran conceived and planned the experiment. Phuong L.A. Nguyen and Ngan H.T. Nguyen conducted the experiment. Truc T.T. Tran and $\mathrm{Du}$ T. Tran were in charge of writing the manuscript.

\section{ACKNOWLEDGMENTS}

This research was partially assisted by instructors from USSH-VNU-HCM and Thu Dau Mot University. We thank our colleagues Truc H. Nguyen and Tra T.H. $\mathrm{Vu}$ for supporting the research design and analysis.

\section{REFERENCES}

[1] A. Alenezi, Barriers to Participation in Learning Management Systems in Saudi Arabian Universities, Education Research International, vol., 2018, 8 pages. DOI: https://doi.org/10.1155/2018/9085914

[2] A. Weleschuk, P. Dyjur, P. Kelly, Online assessment in higher education, Taylor Institute for Teaching and Learning Guide Series. Calgary, AB: Taylor Institute for Teaching and Learning at the University of Calgary, 2019. Retrieved from

https://taylorinstitute.ucalgary.ca/resources/guid es

[3] A.D. Olofsson, J.O. Lindberg, U. Stodberg, Shared video media and blogging online: Educational technologies for enhancing formative e-assessment, Campus-Wide Information System, vol. 28(1), 2011, pp. 41-55. DOI:

https://doi.org/10.1108/10650741111097287

[4] A.F.A. Rahim, Guidelines for online assessment in emergency remote teaching during the COVID-19 pandemic, Education in Medical Journal, vol. 12(2), 2020, pp. 59-68. DOI: https://doi.org/10.21315/eimj2020.12.2.6

[5] C. Hewson, Can online course-based assessment methods be fair and equitable? Relationships between students' preferences and performance within online and offline assessments, Journal of Computer Assisted Learning, vol. 28(5), 2021, pp. 488-498. DOI: https://doi.org/10.1111/j.13652729.2011.00473.x

[6] C. Rolim, P. Isaias, Examining the use of eassessment in higher education: teachers and students' viewpoints, British Journal of Educational Technology, vol. 50(4), 2018, pp. 1785-1800.

DOI: 
[7] C. Gewertz, Transition to online testing sparks concerns, 2013, Accessed January 22, 2018. Retrieved from https://www.edweek.org/ew/articles/2013/10 /30/10pencil_ep.h33.html

[8] D. Boud, Assessment 2020: Seven propositions for assessment reform in higher education. Sydney: Australian Learning Council, 2010. Retrieved

from https://www.uts.edu.au/sites/default/files/Assess ment-2020_propositions_final.pdf

[9] D.E. Stone, G. Zheng, Learning Management Systems in a Changing Environment. book: Handbook of Research on. In V. C. Wang, (Eds.), Handbook of Research on Education and Technology in a Changing Society, United States: Information Science Reference, 2014, pp. 756-767.

[10] E.G. Carmines, R.A. Zeller, Reliability and validity assessment, SAGE publications, 1979.

[11] F.J. García-Peñalvo, A. Corell, V. Abella-García, M. Grande-de-Prado, Recommendations for mandatory online assessment in higher education during the COVID-19 pandemic, in: D. Burgos, A. Tlili, A. Tabacco (Eds.), Radical Solutions for Education in a Crisis Context, Lecture Notes in Educational Technology, Springer, Singapore, 2020, pp. 85-98. DOI: https://doi.org/10.1007/978-981-15-7869-4_6

[12] F.M. Guangul, A.H. Suhail, M.I. Khalit, et al., Challenges of remote assessment in higher education in the context of COVID-19: a case study of Middle East College, Educ Asse Eval Acc 32, 2020, pp. 519-535. DOI: https://doi.org/10.1007/s11092-020-09340-w

[13] I. Fitriyah, M. Jannah, Online assessment effect in EFL classroom: An investigation on students and teachers' perceptions, Indonesian Journal of English Language Teaching and Applied Linguistics, vol. 5(2), 2021, pp. 265-284. DOI: http://dx.doi.org/10.21093/ijeltal.v5i2.709

[14] J. Dermo (2009), e-Assessment and the student learning experience: A survey of student perceptions of e-assessments, British Journal of Educational Technology, vol. 40(2), 2009, pp. 203-214. DOI: https://doi.org/10.1111/j.14678535.2008.00915.x

[15] L. Page, M. Cherry, Comparting trends in graduate assessment: face-to-face vs. online learning, Assessment Update, vol. 30(5), 2018, pp. 3-15. DOI: https://doi.org/10.1002/au.30144

[16] Lei, A. Simon, Gupta, K. Rajeev, College distance education courses: evaluating benefits and costs from institutional, faculty and students' perspectives. Education, vol. 130(4), 2010, pp. 616-631.

[17] M.F. Spivey, J.J. McMillan, Classroom Versus Online Assessment, Journal of Education for Business, vol. 89(8), 2014, pp. 450-456. DOI: https://doi.org/10.1080/08832323.2014.937676

[18] Ministry of Education and Training, Regulations for regular higher education and college programs (Decision № 25/2006/QĐ-BGDĐT), Ho Chi Minh City: Hien M. Hien, June 26, 2006.

[19] Ministry of Education and Training, Regulations for regular higher education and college programs under the credit system (Decision № 43/2007/QĐ-BGDĐT), Ho Chi Minh City: Long T. Banh, August 15, 2007.

[20] Ministry of Education and Training, Regulations for regular higher education programs (Circular № 08/2021/TT-BGDĐT), Ho Chi Minh City: Long T. Banh, March 18, 2021.

[21] M. Kebritchi, A. Lipschuetz, L. Santiague, Issues and challenges for teaching successful online courses in higher education: A literature review, Journal of Educational Technology Systems, vol. 46(1), 2017, pp. 4-29. DOI: https://doi.org/10.1177/0047239516661713

[22] M.L. Hung, C. Chou, C.H. Chen, Z.Y. Own, Learner readiness for online learning: Scale development and student perceptions, Computers \& Education, vol. 55(3), 2010, pp. 1080-1090. DOI:

https://doi.org/10.1016/j.compedu.2010.05.004

[23] N.S. Ali, K. Hodson-Carlton, M. Ryan, J. Flowers, M.A. Rose, V. Wayda, Online education: Needs assessment for faculty development. Journal of Continuing Education in Nursing, vol. 36(1), 2005, pp. 32-38. DOI: https://doi.org/10.3928/0022-0124-20050101-09

[24] N. Tsai, Assessment of students' learning behavior and academic misconduct in a studentpulled online learning and student-governed testing environment: A case study, Journal of Education for Business, vol. 91(7), 2016, pp. 387392.

DOI: https://doi.org/10.1080/08832323.2016.1238808 
[25] People's Committee of Ho Chi Minh City, The temporary suspension of learning activities in Ho Chi Minh City (Dispatch № 1415), Ho Chi Minh City: Duc A. Duong, May 6, 2021.

[26] R. Benson, C. Brack, Online Learning and Assessment in Higher Education, Oxford: Chandos Publishing, 2010.

[27] R.X. Thambusamy, P. Singh, Online assessment: how effectively do they measure student learning at the tertiary level? The European Journal of Social and Behavioural Sciences EJSBS, vol. 30(1), 2021, pp. 63-76. DOI: https://doi.org/10.15405/ejsbs.2021.01.issue-1

[28] S. Bennett, P. Dawson, M. Bearman, E. Molloy, D. Boud, How Technology Shapes Assessment Design: Findings from a Study of University Teachers, British Journal of Educational Technology, vol. 48(2), 2017, pp. 672-682. DOI: https://doi.org/10.1111/bjet.12439

[29] S. Bhebhe, C. Maphosa, An exploration of online assessment in institutions of higher learning, In Ljupka Naumovska (Ed.), The Impact of COVID19 On the International Education System, 2020, pp. 172-183. DOI: https://doi.org/10.51432/978-1-8381524-0-6_13

[30] S. Khan, R.A. Khan, Online assessments: Exploring perspectives of university students, Education and Information Technologies, vol. 24(1), 2019, pp. 661-667. DOI: https://doi.org/10.1007/s10639-018-9797-0

[31] S. Koç, X. Liu, P. Wachira, Assessment in online and blended learning environments-information age publishing, Information Age Publishing, Inc., 2015.

[32] S.H.P.W. Gamage, J.R. Ayres, M.B. Behrend, E.J. Smith, Optimizing Moodle quizzes for online assessments, International Journal of STEM Education, vol. 6(27), 2019. DOI: https://doi.org/10.1186/s40594-019-0181-4

[33] USSH-VNU-HCM, Online teaching (Notification № 250/TB-XHNV-ĐT), Ho Chi Minh City: Trang T. T. Ngo, May 7, 2021. 